\title{
Article
}

\section{Delving into the Unknown: An experience of doing research with d/Deaf prisoners}

Kelly-Corless, Laura

Available at http://clok.uclan.ac.uk/24646/

Kelly-Corless, Laura ORCID: 0000-0002-4712-5850 (2020) Delving into the Unknown: An experience of doing research with d/Deaf prisoners. Qualitative Inquiry, 26 (3-4). pp. 355-368. ISSN 1077-8004

It is advisable to refer to the publisher's version if you intend to cite from the work. http://dx.doi.org/10.1177/1077800419830133

For more information about UCLan's research in this area go to

http://www.uclan.ac.uk/researchgroups/ and search for <name of research Group>.

For information about Research generally at UCLan please go to http://www.uclan.ac.uk/research/

All outputs in CLoK are protected by Intellectual Property Rights law, including Copyright law. Copyright, IPR and Moral Rights for the works on this site are retained by the individual authors and/or other copyright owners. Terms and conditions for use of this material are defined in the policies page. 


\section{Qualitative Inquiry}

\section{Delving into the Unknown: An experience of doing research with d/Deaf prisoners}

\begin{tabular}{|c|c|}
\hline Journal: & Qualitative Inquiry \\
\hline Manuscript ID & QI-18-235.R1 \\
\hline Manuscript Type: & Research Article \\
\hline Date Submitted by the Author: & 13-Sep-2018 \\
\hline Complete List of Authors: & Kelly, Laura; Harris Building, Lancashire Law School \\
\hline Keywords: & $\begin{array}{l}\text { prison, Qualitative Research < Methodologies, Interviewing }< \\
\text { Methodologies, Deaf, communication }\end{array}$ \\
\hline Abstract: & $\begin{array}{l}\text { This article acts as a reflexive account of my experience of doing } \\
\text { qualitative research with d/Deaf people in a prison setting. This research } \\
\text { was the first in England and Wales (excluding small-scale unpublished } \\
\text { undergraduate dissertations) to include semi-structured interviews with } \\
\text { multiple d/Deaf prisoners, and thus the journey documented is both } \\
\text { innovative and unique. Because I was entering unmarked territory } \\
\text { methodologically, my experience was laden with obstacles, as is discussed } \\
\text { throughout. Key issues explored relate firstly to the process of gaining } \\
\text { access to d/Deaf prisoners, secondly to researcher-participant language } \\
\text { barriers, and thirdly to issues of ethics and authenticity generated by the } \\
\text { Deaf participants' preference for a visual language (British Sign Language) } \\
\text { in a setting like prison. Guidance is given throughout about how to } \\
\text { overcome complex methodological issues, and concluding remarks include } \\
\text { a set of recommendations for prospective researchers. }\end{array}$ \\
\hline
\end{tabular}

\section{SCHOLARONE}

Manuscripts 


\section{Delving into the Unknown: An experience of doing research with $d /$ Deaf prisoners}

Dr Laura Kelly.

Lecturer in Criminology, University of Central Lancashire

Highest degree: $\mathrm{PhD}$

Address: Harris Building, University of Central Lancashire, Preston, PR1 2HE

Email: LKelly13@uclan.ac.uk

\section{Biographical statement}

Laura is a lecturer in Criminology at the University of Central Lancashire who specialises in prison studies. She was awarded her PhD for the thesis entitled 'Silent Punishment: The experiences of $d / D e a f$ prisoners' in July 2017, and won the Prison Service Journal outstanding article of the year 2017 based on an article that outlines findings from this. Laura facilitates an annual student/prisoner debating programme at HMP Kirkham called 'Debating Differences'.

\section{Abstract}

This article acts as a reflexive account of my experience of doing qualitative research with $d /$ Deaf people in a prison setting. This research was the first in England and Wales (excluding small-scale unpublished undergraduate dissertations) to include semi-structured interviews with multiple $d /$ Deaf prisoners, and thus the journey documented is both innovative and unique. Because I was entering unmarked territory methodologically, my experience was laden with obstacles, as is discussed throughout. Key issues explored relate firstly to the process of gaining access to d/Deaf prisoners, secondly to researcher-participant language barriers, and thirdly to issues of ethics and authenticity generated by the Deaf participants' preference for a visual language (British Sign Language) in a setting like prison. Guidance is given throughout about how to overcome complex methodological issues, and concluding remarks include a set of recommendations for prospective researchers. 
The fact that prison as an institution is designed to punish and constrain (Crewe, 2011) and is largely hidden from the public eye, means that it presents somewhat of an enigma to the majority of those who have not been confined within its walls (Sparks, Bottoms \& Hay, 1996). In order to unravel some of the mystery surrounding the realities of prison life, in recent decades there has been a surge in prison research and with this has come an assortment of accounts from researchers about the pathways taken through their research. The form that these accounts take varies significantly. While some researchers simply provide an outline of the research design utilised, others endeavour to provide detailed reflexive accounts of their research journeys, considering factors such as the issues that they faced (King and Liebling, 2008; Stevens, 2013; Sloan \& Wright, 2015), their subjective role in the research process (Liebling, 1999; Phillips, 2012; Hammersley, 2015) and the impact that they had on the findings (Drake, 2012; Rowe, 2014). These in-depth accounts can be of particular use to prospective prison researchers, affording them an insight into the realities of doing prison research, and some of the "methodological landmines" (Schlosser, 2008: pp. 1501) that the prison environment generates.

This article acts as a reflexive account of my journey through my doctoral research which examined the experiences of hard of hearing $(\mathrm{HoH})$ and d/Deaf prisoners in England and Wales. An exploratory qualitative research design was utilised throughout, and semi-structured interviews with prisoners and staff members were the main form of data collection. In many ways my experiences were similar to those of other researchers; moulded unavoidably around the unique nature of the prison environment, and the challenges it presents. However, the fact that my focus was on $d /$ Deaf prisoners created a myriad of additional methodological complications, as unlike many other minority groups in prison in England and Wales, those who are d/Deaf have rarely been considered empirically.

Prior to this study, the most comprehensive research carried out in this area was by McCulloch $(2010,2012)$ who as part of his MA, looked at the experiences of this group and considered whether their rights were upheld in prison. Due to access issues and time constraints, McCulloch collected his data by writing letters to participants rather than carrying out interviews, which he acknowledges could have impeded the richness of the data. This meant that at the time of this study, there was little information available about how to go about carrying out research of this type, and as such the path that lay before me was largely unmarked. 
Because of this, the research process became laden with unexpected obstacles, including issues relating to gaining access to $\mathrm{d} /$ Deaf prisoners, problems associated with researcher-participant language barriers, and added complexities in the process of recording and transcribing interviews where the participant communicated in British Sign Language (BSL). While issues relating to communication have been experienced by individuals carrying out research with d/Deaf people in other social settings (Young \& Hunt, 2011; Sutherland \& Young, 2014; Wilson \& Winiarczyk, 2014), throughout this article it is shown that the secure and restricted nature of the prison environment often exacerbates such issues, and also generates further methodological complications. It is important to acknowledge that my status as a hearing person with limited comprehension of BSL also enhanced communication related difficulties, as is discussed throughout.

The first section of this article lays out the aims of the research and the research method used in more detail. After this, my journey through the fieldwork process is documented, with key themes being access, data collection, recording and transcription, ethical considerations, and the management of inevitable subjectivity. While links are made to the methods and experiences of other prison researchers where relevant, I also discuss the extra complications I encountered throughout and the ways I attempted to navigate and overcome them. This is important as it will provide an indication for other researchers about what to expect if they are intending to carry out qualitative research with $d /$ Deaf people in a prison setting.

\section{The Research: Aims and Method}

The primary aim of this research was to provide a more rigorous and comprehensive account of the lives of d/Deaf prisoners in England and Wales than was already available. In order to address this aim, meaningful consideration was given to the role of 'imported' identity, and the complex layers of $d /$ Deafness ${ }^{1}$. As such, the experiences of medically deaf and culturally and linguistically Deaf prisoners were examined separately ${ }^{2}$. This

\footnotetext{
${ }^{1}$ This is a key weakness of McCulloch's study. While he does provide the most comprehensive account of the problems faced by $d$ /Deaf prisoners in the UK, he fails to differentiate meaningfully between the experiences of prisoners who are deaf, and those who are culturally and linguistically Deaf.

${ }^{2}$ For the purposes of clarity, the two terms must be defined. Medical deafness is a clinical condition, which sits on a spectrum according to the quietest sound that an individual is able to hear. The extent to which a person is medically deaf varies significantly from those whose hearing is only slightly impaired, to individuals who are hard of hearing $(\mathrm{HoH})$, and finally to those who are severely deaf (Action on Hearing Loss, N.D). In contrast to this, cultural definitions of d/Deafness focus on identity, and the way in which an individual identifies with their $d$ /Deafness. Thus, individuals who are culturally and linguistically Deaf identify as being part of a culturally distinct minority group, who commonly use British Sign Language (BSL) to communicate (Padden, 1980). These individuals are seen as being part of the Deaf Community, which is comprised of people who are proud to be Deaf and share the same language, similar cultural values and common life experiences (Leigh, 2009). This contrasts significantly with those who are medically deaf (but not culturally Deaf) who usually view their deafness as a problem, and commonly feel stigmatised by it (Higgins, 1980).
} 
distinction between medical deafness and cultural and linguistic Deafness was pivotal to the research, and contributed to many of the methodological complications I experienced. These complications stemmed from the fact that individuals who are Deaf usually communicate and behave in largely visual ways.

In a similar vein to other prison studies (Jewkes, 2002; Scott, 2006; Phillips, 2012), the research took a qualitative line of enquiry. The primary method of data collection was semi-structured interviews, which took place at seven adult male prisons in England. 27 interviews were carried out on an individual basis; 17 with $\mathrm{HoH} / \mathrm{d} /$ Deaf prisoners and 10 with staff members who had worked with them. Of the prisoners interviewed, seven were culturally and linguistically Deaf, five severely deaf and five $\mathrm{HoH}$. A group interview was also carried out which involved four culturally and linguistically Deaf participants, each of whom had been interviewed individually as well. All interviews were recorded using a Dictaphone, and in instances where a participant's first language was BSL, a qualified interpreter was present ${ }^{3}$.

Observation was used as a secondary research method, and as such, throughout the fieldwork process observations were made at all of the establishments entered. These observations were then recorded in a journal, where a detailed account of my time at each prison was provided, including details about sights, sounds, interactions and relationships. Using observation to supplement interviews enhanced the quality of the research in that it helped me to gain a richer understanding about prison life (for similar findings, see also Scott, 2006; Crewe, 2009), and the position of d/Deaf prisoners within it.

An explorative qualitative approach was deemed most appropriate given the fact that so little empirical research had been carried out with this particular group in prison (Mason, 2002). The use of semi-structured interviews proved effective as it enabled a certain level of consistency to be maintained within the findings (Scott, 2006), whilst also allowing for a series of open-ended questions to be asked. This afforded participants the opportunity to express their opinions in their own way, in a conversational format. The lack of strict structure gave me the flexibility to probe more into certain responses, which was useful in terms of both clarification and elaboration (Liebling, 1999; May, 2001). Room to clarify was particularly important during interviews with culturally and linguistically Deaf participants, who often misinterpreted the question that was being asked via the interpreter. Consequently, they would often provide confusing responses which required

\footnotetext{
${ }^{3}$ The interviews were preceded by a pilot staff member interview and a pilot prisoner interview, where I tested out my interview schedules. The pilot interview with the prisoner is discussed further later in the article.
} 
further probing from me and re-interpreting from the interpreter (for similar findings see Murray \& Wynne, 2001; Young \& Hunt, 2011).

When the fieldwork began I had not planned to carry out any group interviews. However, during my time at HMP Bowdon ${ }^{4}$ where I interviewed five culturally Deaf prisoners, it became clear that a number of participants were under the impression that they were going to be interviewed as a group. These individuals were eager to participate in a joint discussion, and thus, a group interview was organised on the spur of the moment, taking place later the same day with four of the participants. This proved invaluable in terms of the richness of the data collected, as it transpired that the participants were much more comfortable discussing their experience at the prison while they were with other Deaf people, and often reminded each other of things that had not been mentioned within individual interviews (see also Matthews \& Ross, 2010; Bryman, 2012).

\section{The Impossibilities of Accessing an Unknown Population}

After outlining the chosen methods of data collection, consideration is now given to the process of negotiating access to the participants. 'Getting in' to prison creates issues for most prison researchers to some extent (see for example, Stevens, 2013; Sloan \& Wright, 2015; Wincup, 2017), and like many before me, gaining access to the research sample was perhaps the most complex "methodological landmine" (Schlosser, 2008, pp. 1501) that I faced. Although I did have some prior experience of carrying out prison research and had engaged with relevant literature, in reality the intricacy of the process transcended my expectations. Such intricacies were compounded by issues relating to my chosen sample, as to be discussed below.

In order to gain access to the research sample I was required to go through a centralised National Offender Management Service (NOMS) ${ }^{5}$ application process. This began with the submission of an application form ${ }^{6}$ along with a copy of my CV, ethical clearance from the University of Central Lancashire (UCLan) ${ }^{7}$ and drafted consent forms and information sheets to the National Research Committee (NRC) ${ }^{8}$. Certain aspects of the

\footnotetext{
${ }^{4}$ All prison names in this article are pseudonyms.

${ }^{5}$ Now called Her Majesty's Probation and Prison Service (HMPPS).

${ }^{6}$ Within the application form I was required to supply information about the aims of the project, the benefits that it would have for the Prison Service, whether it would add to existing literature, its methodology and any ethical issues (amongst other things).

${ }^{7}$ Inclusion of ethical approval was problematic as the UCLan were unwilling to provide ethical approval until I could show evidence of approval from NOMs. In order to overcome this issue, I applied for ethical approval in principle which UCLan agreed to grant. Once NOMS clearance had been given, I then re-applied to the ethics committee for full approval.

${ }^{8}$ The NRC was a subsection of NOMS that assessed research applications based upon a number of criteria, including the
} 
application form were difficult simply because I was not able to provide the information that was being requested. This related primarily to questions about the proposed methodology of the research, as within this there was a requirement to discuss the size of the research sample, and to provide a list of the establishments that I would be entering. This was particularly challenging given that there is currently no legal requirement for the Prison Service to keep records of numbers and/or locations of d/Deaf prisoners (Kelly, 2017). Without this information I was unable to specify with any certainty how many people I wanted to interview, or where such interviews would take place.

This obstacle could have been overcome by contacting prisons individually and requesting the information. However, when I attempted to make contact, establishments were usually unwilling to respond in any meaningful way because I did not have official approval. As an alternative I used information provided from other sources ${ }^{9}$ to collate a list of establishments within which I had been advised one or more d/Deaf prisoners had resided in the preceding year. I also provided a predicted sample size of a minimum of eight d/Deaf prisoners and stated that I would be interviewing staff members but that I was unable to provide specific sample numbers. Aware of the vagueness of this estimation, I also specified that once clearance had been gained, letters would be sent to the governor of every prison establishment in England and Wales to confirm whether there were any $d /$ Deaf prisoners there.

The application was initially approved 'Subject to Modifications', with the primary condition of the approval being the clarification of sample sizes. In order to gain such clarity, a letter requesting information about d/Deaf prisoner numbers was sent to the governor of every establishment in England and Wales. Although the letter contained proof of the approval with modifications, when I began to receive responses it became clear that many prisons were unwilling to provide any information without full approval. This created a frustrating tautological cycle, in that I could not obtain full approval without a clearer conception of sample sizes, and the only way I could get such information was from the prisons themselves.

Further hurdles then arose when NOMS contacted me stating that they had received correspondence from institutions that were not included in my proposed prison list. I was advised that if I wanted to contact other

extent to which the proposed research fits with NOMS priorities, the applicant's research experience and the demand that the research will have upon prison resources.

${ }^{9}$ These included individual prison staff members, charities, and other researchers. 
prison because the allocated contact went on long-term sick, only to be replaced by a substitute contact who then also went on long-term sick. Another reason for delayed correspondence was attributed to public sector budget cuts, and, mirroring the experiences of King and McDermott (1995) and Genders and Player (1995) whose research was affected by wider organisational changes, numerous allocated contacts advised that as a result of nationwide organisational benchmarking they were so understaffed that they did not have time to respond or had been seconded to other roles.

Furthermore, the chaotic and unpredictable nature of the prison environment meant that access related issues continued to arise even after establishments had confirmed their willingness to be involved in the research, and had specified the presence of an appropriate participant. Like Davies (2011) I found that prior commitments on behalf of staff members often made it difficult to organise a specific date for interviews to take place. Although I knew that I needed to be flexible and willing to adapt to the daily workings and institutional timetable of each prison (Martin, 2000; Wincup 2017), such flexibility was often not an option. The reason for this centred around the necessity for a BSL interpreter in instances where I would be interviewing a Deaf prisoner, as although I was able to be sufficiently flexible, my interpreter ${ }^{11}$ who had other commitments, was not. On some occasions this meant that I had little choice but to decline suggested interview dates with the hope that they could be rescheduled. However, in one instance my interpreter was not able to commit to attending the interview, and the prison was not able to reschedule. Therefore, in order to avoid missing out on the opportunity to interview a culturally and linguistically Deaf prisoner I used the services of a different qualified BSL interpreter, as to be discussed later in the article.

Even at the point where an interview time and date had been arranged, further complexities in the access process continued to arise. Originally I had been interested primarily in the experiences of culturally and linguistically Deaf prisoners (and medically deaf prisoners to a lesser extent), and had made this clear in all correspondence with prisons. However, this intended utilisation of a purposive sampling frame was undermined by the fact that my allocated contacts often had little conception of the multiple layers of

\footnotetext{
${ }^{11}$ My interpreter was one of my PhD supervisors, who was a qualified BSL interpreter and had agreed to interpret for me in order to avoid excessive research costs. Other members of my supervisory team were concerned that this may be perceived by some as a conflict of interest, and thus, in order to address this concern, advice was sought from the university. This issue was initially raised with the head of the UCLan's ethics committee and then the university's research committee who advised that "The supervisory team interpret many aspects of a student's research - What he is doing is practical, necessary and he knows how. Unless he misinterprets the answers deliberately and mis-signs the questions -1 see no issue". It was then advised that the University would also take this stance in the future.
} 
$d /$ Deafness, and thus were ill-equipped to distinguish between those who were medically deaf and those who were culturally and linguistically Deaf. This was compounded by the ambiguity of the data available on NOMIS, which many of my contacts were relying on. Without a formal distinction between Deafness and deafness in the NOMIS data, many contacts then labelled prospective participants based upon their own understanding of d/Deafness which was often limited. For example, prior to my pilot prisoner interview I had been advised that the participant was culturally and linguistically Deaf and that a BSL interpreter would be required. However, upon arrival it became apparent that he was in fact partially deaf and had residual hearing in one ear. He was unable to communicate in BSL and relied upon a hearing aid and the ability to lip read when conversing, which meant that my interpreter had attended unnecessarily and that many of the questions in my pilot interview schedule were not relevant. This pattern continued throughout the research process, meaning that I had to prepare for multiple eventualities prior to each interview. It also altered the make-up of my sample, extending it to include more medically deaf participants than envisaged and a number of $\mathrm{HoH}$ participants. Despite initial doubts, this proved advantageous as it allowed for in-depth consideration to be given to the role of imported identity, which, as already mentioned, then went on to become pivotal to the research.

\section{The Intricacies of Interviewing}

Throughout the interviews, similar themes usually arose due to the nature of the questioning. However, interviews were affected by a number of key factors, including the extent to which an individual was d/Deaf, institutional involvement, the participant's method of communication, their role in the prison, and the way they perceived me, the researcher. Each of these factors will now be discussed in turn.

\section{The impact of identification}

The level to which an individual was $d /$ Deaf had a significant impact on their openness during interviews. Most of the $d$ /Deaf prisoners interviewed were open and engaged during their interviews, appearing to relish the opportunity to discuss their lives, perceptions and problems with an interested outsider (for similar findings see also Bosworth, Cambell, Demby, Ferranti \& Santos, 2005; Stevens, 2013). This was particularly true for those who were culturally and linguistically Deaf, as these individuals are commonly deprived of meaningful communication in prison (Kelly, 2017). Because of this they appeared to perceive their interview as an 
opportunity to get their point of view across to somebody who understood them, and on some occasions, just to communicate generally. This is highlighted below in an interview abstract:

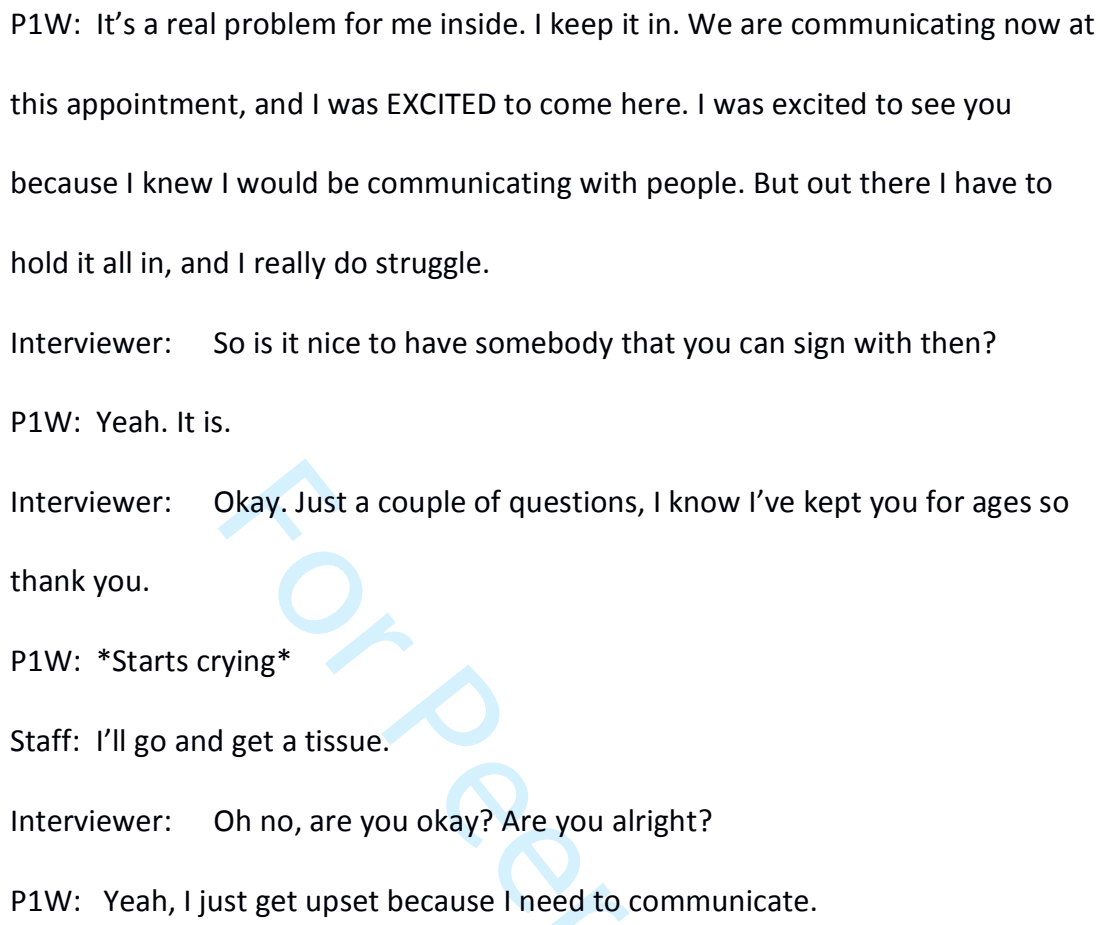

The $\mathrm{HoH}$ participants were much less willing to engage fully during interviews, and were at times curt and dismissive when asked about their hearing loss. Central to this was the fact that they often felt stigmatised by it, and were embarrassed (despite having agreed to be interviewed) (Kelly, 2018). While this was awkward at the time, it proved beneficial as their responses highlighted clearly how negatively they felt about their hearing loss, which then allowed me to explore with them how these feelings impacted on their lives in prison.

$\underline{\text { Institutional Influence }}$

The secure, highly regulated and restrictive nature of the prison environment meant that all interviews were affected by the institution to some extent. The institutional timetable often dictated the duration of an interview, with a number of interviews being cut short because of other priorities (Martin, 2000; Wincup \& Hucklesby, 2007; Wincup, 2017). Also, the fact that prisoners have to be in their cells at certain points, and can only move around the prison at very specific times created difficulties, particularly at HMP Bowdon where I was interviewing four Deaf prisoners in a row. Staff at the establishment had created an interview timetable 
right time. This was troublesome as the slots were much too short; meaning that a number of interviews were brought to an end abruptly because they had exceeded their allocated time allowance. The fact that this was during interviews with Deaf participants created particular difficulties given that these interactions take longer anyway because all communication has to be mediated by a BSL interpreter (Almalik, Kiger \& Tucker, 2010; Ingvarsdotter, Johnsdotter \& Ostman, 2010) ${ }^{12}$.

While all of the staff member interviews took place in a private location, all but three of the prisoner interviews were conducted in the presence of a prison official. Like others, I found that this lack of privacy often affected the interview (Scott, 1996; Hucklesby \& Wincup, 2007); potentially inhibiting disclosure, and at times directly affecting the topics discussed. In terms of the latter point, there were instances where present staff members became involved in the dialogue between me and the participant. This was particularly prominent during one interview where the staff member repeatedly interrupted the participant when he was critical of his treatment at the prison in order to provide an explanation for such treatment. Another example occurred when a present staff member attempted to steer the discussion on occasions where he thought that the nature of the prisoner's comments was not appropriate/relevant. He would do this by interjecting with remarks such as "Should we get back to the deafness?" when the participant was discussing his experience of prison more generally, which then caused him to apologise and change the subject. This intrusion was detrimental to the quality of the data, as in these instances the prisoner was talking candidly and providing rich insight into some of the realities of prison life.

\section{Communication}

The method of communication used in each interview had a significant impact on the interview format and the extent to which I was able to build rapport with participants. The fact that the interviews were carried out with participants across the hearing-Deaf spectrum meant that methods of communication varied from interview to interview. Communication during the interviews with staff members, deaf/HoH prisoners who had adequate hearing aids and prisoners who were only mildly $\mathrm{HoH}$ was straight-forward because they all communicated verbally, and could hear enough to interact with relative ease. However, in instances where individuals were

\footnotetext{
${ }^{12}$ This could have impeded the quality of the data collected. However, the fact that these interviews were followed by a group interview combatted this, as it gave participants the opportunity to discuss their points in more depth.
} 
more severely $\mathrm{HoH} / \mathrm{deaf}$ and did not have access to adequate hearing aids, communication became much more difficult. Although the method of communication itself was the same for all of these prisoners i.e. they all communicated verbally, our interactions were more disjointed because they could not hear sufficiently. This made it more difficult to build rapport as I often had to continuously repeat myself to individuals who would mishear questions and provide unrelated answers (see also Young \& Hunt, 2011). For example, one participant was severely deaf in both ears but had no access to hearing aids and had not learnt to lip read since going deaf. As a result of this I struggled to interview this participant and felt awkward throughout the duration of our interaction.

My inability to utilise BSL beyond a very basic level had a significant impact on the interviews with the culturally and linguistically Deaf participants, all of whom preferred to communicate in this way. Because of this language barrier, I found it extremely difficult to build rapport with a number of the Deaf interviewees (see also Murray \& Wynne, 2001; Almalik et al., 2010; Ingvarsdotter et al., 2010; Young \& Hunt, 2011), as shown here in an extract from my fieldwork journal:

It is very hard to conduct any interview with someone who doesn't speak your language, never mind when you are trying to ask somebody about their personal experiences and private emotions; You lose all the non-verbal cues and interactions and this makes the flow of the interview less conversational and more question answer question answer question answer $\left(19^{\text {th }}\right.$ February 2015).

Furthermore, even though participants had been made aware that an interpreter was present in order to bridge the communication barriers between interviewer and interviewee and would not be actively involved in the dialogue between the two, they often misinterpreted this. Rather, because it was the interpreter who was providing them with the information that they could understand, participants often appeared to think that the information was actually coming from them. Because of this, on multiple occasions participants attempted to communicate with the interpreter. For example, during one interview the participant focused his responses at the interpreter rather than myself and at one point asked him whether he ever went to Deaf clubs. This was highlighted further during another interview where I had similar problems, as shown in another extract from my fieldwork notes: 
If anything I felt like the prisoner was warming to the interpreter because it was

they who they could communicate with, rather than me even though they were my words. As a result of this I felt almost like a third wheel in my own interview ( $7^{\text {th }}$ May, 2015).

Situations such as this were frustrating as although I attempted to build a rapport with these participants, without a common language this was very difficult.

The role of the researcher

Before beginning the fieldwork, I was aware that the level to which a participant engages in research is contingent upon the identity they give to the researcher and what they perceive their intentions to be (Morris \& Morris, 1963; Emery, 1970; Sparks et al., 1996; Stevens, 2013; Drake \& Harvey, 2014; Rowe, 2014). With this in mind my main concern was how my status as a hearing person might impact upon the way the culturally Deaf participants would respond to me. This concern was based on advice from my supervisory team and information drawn from existing literature, both of which suggested that their prior experience with hearing people may cause the Deaf participants to be suspicious of me, and unwilling to engage (Atherton, Russell \& Turner, 2001; Harris, 2010; Young \& Hunt, 2011; Stone \& Mason, 2012). Fortunately, none of the Deaf participants involved in the research were outwardly resentful or uncooperative. Rather, it appeared that any preference for a Deaf interviewer was outweighed by a desire to get their story across to anyone who would listen, irrespective of their status.

I was also aware that participants often misinterpret the identity of researchers, and presume them to be something that they are not (Morris \& Morris, 1963; Emery, 1970; Sparks et al., 1996; Crewe, 2009; Phillips, 2012; Stevens, 2013; Scraton \& Moore, 2013; Scott, 2015a). Therefore, in order to minimise any ambiguity about my identity I made it clear within information sheets and consent forms, and at the beginning of each interview that I was from a University and was carrying out an independent study without any underlying agenda. As part of this, I specified that I was aiming to contribute to some positive change for d/Deaf people in prison. While I had assumed that this would help to ensure clarity about my motive, it became apparent that in the context of the culturally and linguistically Deaf prisoners, the inclusion of 'contribute to some positive change' led to misconceptions about the scope of my role and authority. All of these individuals were 
experiencing significant issues in prison as a consequence of a lack of resource allocation or Deaf awareness (Kelly, 2017; 2018). Because of this they were severely isolated, frustrated and anxious, and desperate for changes to be made. Thus, my mention of positive change led to an expectation that I would be able implement alterations for them, and led to questions being asked as to when they would begin to see improvements in provisions. Although I explained clearly that I did not have the authority to implement any significant changes, this misconception created significant feelings of guilt, as shown below:

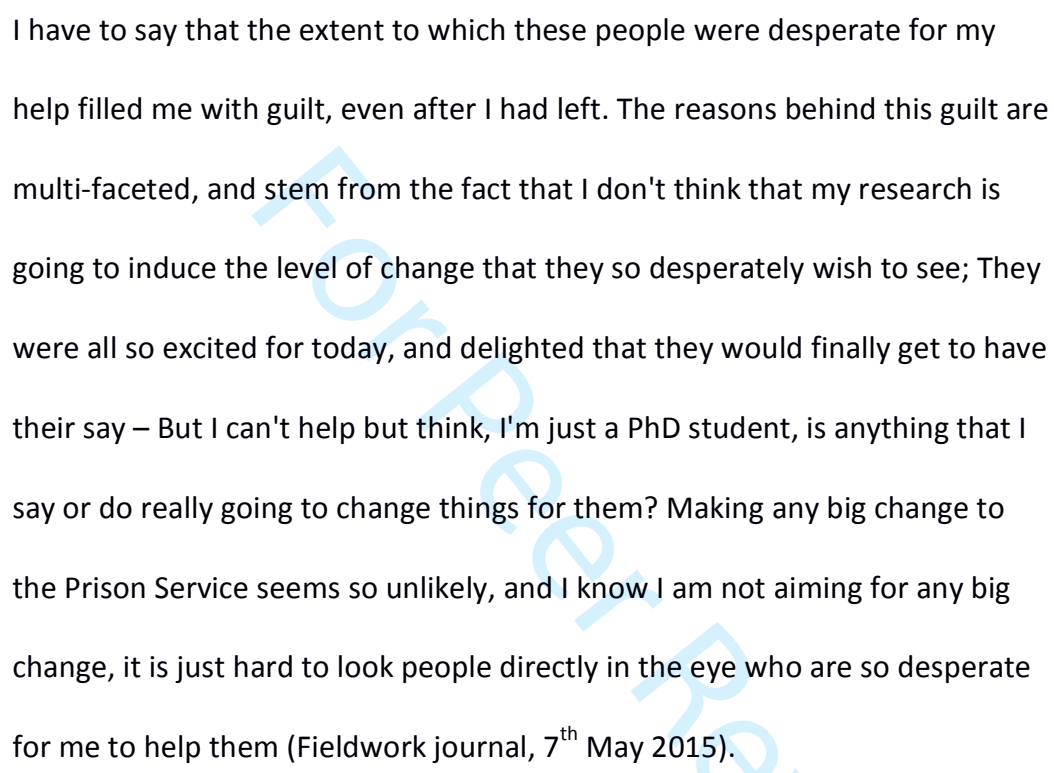

The fact that my sample included prisoners and staff members meant that the process of effectively managing participants' perceptions was difficult for other reasons as well, in that I had to try and appear simultaneously trustworthy and 'on the side' of two distinct groups, whose values and principles are inherently conflicting (Scott, 2006; Crewe, 2009; Stevens, 2013; Hammersley, 2015). While some prison researchers discuss having significant problems negotiating a balance between the groups (Sparks et al., 1996; Stevens, 2013; Rowe, 2014), my experience was much more straightforward, and mirroring the experience of Crewe (2009), cooperation from both groups meant that I did not feel required to choose between the two. However, in instances where interviewees were critical of the behaviours of the other group, I was careful to be as pragmatic as possible, and in order to do this I adopted Stevens' (2013) belief that it is "entirely possible to be on 'both sides' but not at the same time" (pp. 44). I also made a continued effort to remain impartial if asked about my opinions on prison-related matters, and to appear neutral even when I felt as though I was 'taking 
sides' internally (Crewe, 2009; Stevens, 2013). While the research was clearly prisoner oriented, the inclusion of staff members in the research sample certainly strengthened the validity of findings, in that on numerous occasions their perceptions reinforced the data collected from the prisoners and often reaffirmed complaints of discrimination and unfair treatment.

Even after attempting to ensure that any ambiguity about my identity was removed, my presence inevitably altered the way that participants behaved (for similar findings, see also Jewkes, 2002; Phillips, 2012; Earle, 2014). While many prison researchers have found that their gender affected the way that participants responded to them (Morris \& Morris, 1963; Gelsthorpe, 1990; Liebling, 1999; Jewkes, 2002; Phillips, 2012; Stevens, 2013), I did not feel as though this was the case. Yet, like Sloan and Wright (2015) I did suspect that my age influenced the behaviour of certain participants, particularly staff members. On numerous occasions participants asked about my age, and some also enquired as to whether I was an undergraduate student doing my dissertation. This was frustrating as I felt as though participants were taking me less seriously than they would an older, more experienced researcher.

\section{Recording and Transcription}

After discussing the interview process, consideration is now given to the process of recording and transcribing the data, as this part of the research process was also littered with complications. All interviews were recorded with a Dictaphone, and although this proved to be sufficient for 21 of the 28 interviews, problems arose when the Dictaphone was used to record the interviews carried out with culturally and linguistically Deaf prisoners. The visual nature of BSL meant that the original data generated during these interviews were in a visual rather than verbal form, and thus the Dictaphone recorded only the interpreter's mediated version of the responses rather than the original responses themselves. I was conscious of this prior to applying for NOMS approval, and within my application indicated that the use of a visual recording device would be preferential, for ensuring complete authenticity (Atherton et al., 2001; Young \& Hunt, 2011; Stone \& West, 2012; Wilson \& Winiarczyk, 2014). Despite this request, none of the establishments included in the research were willing to allow me to bring in a video recorder, which meant that a Dictaphone had to suffice.

While an audio recording would have been sufficient if I could have guaranteed that the interpreter was providing an exact translation of the interactions, in reality such an assurance was not possible (for discussions 
on this see Roy, 1992; Wadensjö, 1998; Atherton, et al., 2001; Harrington \& Turner, 2001; Young \& Hunt, 2011;

Stone \& West, 2012). Rather, the interpreter was the only party who could understand both myself and the participant. Consequently, the extent to which the data collected was authentic hinged largely upon the interpreter's performance during the interview (Harrington \& Turner, 2001; Stone \& West, 2012). Therefore, in order to minimise any issues that could arise in relation to this it was important to ensure that the interpreter used was both sufficiently qualified and reputable.

As previously noted, two interpreters were used during the research process, both of whom were fully qualified and registered with the National Registers of Communication Professionals working with Deaf and Deaf blind People (NRCPD) ${ }^{13}$. The fact that the primary interpreter was also one of my PhD supervisors meant that he was aware of the nature of the research and the role that he would be taking. However, because an external interpreter was utilised at one establishment, it was important to ensure that she was clear about the aims of the research and the remit of her role. In order to do this, copies of the relevant interview schedule, information sheet and consent form were sent to her beforehand. I also made sure to contact her via phone and email in the days prior to the interview to ensure that any queries or issues that she may have had regarding the research were resolved. She was made aware of the use of a Dictaphone, and that she must interpret clearly in order to ensure that her voice was decipherable on the recording. After the interview was over I then gave her the opportunity to discuss any issues that she may have had during the interview process, of which there were none.

After they were completed, all of the interviews were transcribed with the aim of being as close to verbatim as possible. Although the majority of the recordings were transcribed with relative ease, the interviews that took place with a number of the culturally Deaf prisoners proved to be extremely difficult to transcribe, in that as well as using BSL to communicate, some Deaf people choose to verbalise simultaneously ${ }^{14}$. This was problematic for transcribing because the verbalisations of a number of the participants were often unclear,

\footnotetext{
${ }^{13}$ The NRCPD is a service which "exists to protect the public by regulating communication and language professionals who work with deaf and deafblind people" by holding registers of these people (NRCPDa, N.D: Unpaginated). In order to become registered with the NRCPD an individual must have successfully completed an approved course, must continue their professional development and must abide by the Code of Conduct as outlined by the service. This code of conduct outlines expectations for how registered professionals must behave if they are to remain on the register, and requires them to act completely impartially in all interpreting settings, translating faithfully and accurately to the best of his/her ability without adding or taking anything away from the source message (NRCPDb, N.D).

${ }^{14} \mathrm{~A}$ primary reason for this is that they had been taught to speak as children in hearing schools or by hearing parents (Marschark, 2009)
} 

decipher what the interpreter was saying because I could only hear the verbalisations of the Deaf individual. In order to overcome this, I listened to certain extracts repeatedly at a slower speed, which on many occasions allowed me to make out what was being said. However, even after being listened to by a BSL interpreter (interpreters are seen as being more equipped to comprehend Deaf voices), a number of extracts remained indecipherable and therefore had to be omitted from the transcripts.

Transcription was particularly difficult in the context of the group interview. Because it was organised on the spur of the moment, we (myself and the interpreter) had little opportunity to discuss ways of ensuring that the interpretations would be as clear as possible on the recording. In an attempt to alleviate issues of indecipherability, immediately prior to the interview we agreed that he would state the name of the participant he was interpreting for at the beginning of each interpretation. However, once the interview started it became clear that he was going to struggle to provide all the necessary translations because of the way the participants were communicating. Despite all being Deaf, each interviewee had a slightly different way of interacting; two participants signed and spoke (P1B and P5B), one relied entirely on BSL (P2B), and one signed whilst vocalising very loudly and incoherently (P4B). This meant that the interview was comprised of extremely complex interactions, which made effective and accurate interpreting difficult. For example, at onepoint the interpreter was translating the spoken words of P1B to P2B and P4B who only used BSL, and while this alone may have been fine, I found P1B's voice extremely difficult to decipher and therefore was forced to say "Pardon?" whilst the interpreter was interpreting. At this point he would have to come in and translate the words for me, and therefore was simultaneously interpreting for both me and a number of the participants. This meant that there was little opportunity to state the participant's names at the beginning of each interpretation, and therefore when listening back to the recording, it was difficult to decipher who was saying what. Furthermore, again the fact that a number of the participants vocalised as well as signing meant that on the recording, not only were complex and flurried interpretations taking place, but they were being obscured by the voices of the Deaf participants. In consequence, while most of the recording was successfully transcribed, in instances of uncertainty I was again forced to omit certain extracts. 


\section{Ethics}

Ethical approval to carry out the research was obtained from NOMS in October 2014, and UCLan in November 2014, and all relevant ethical guidelines were followed during the research process. While confidentiality, anonymity, consent and the welfare of participants were all important ethical considerations, focus is given here to those that relate specifically to doing research with $d$ /Deaf prisoners, the first of which relates to consent. In order to ensure that all participants were fully informed about the nature of the research, an information sheet disclosing all the relevant information about the study and a consent form were sent to each establishment at least two weeks prior to my date of entrance (something which was also stipulated by NOMS as a condition of the research approval). In order to ensure that the documents were accessible to the culturally and linguistically Deaf participants (who often cannot read or write), visual copies were also made available (for discussions on this see Young \& Hunt, 2011). The creation of these involved an interpreter being videoed translating the information into BSL, whilst another person simultaneously read the contents aloud in English. The reason that the content was also verbalised was to avoid potential security issues that could arise as a result of a document entering the prison and being made available to prisoners, that staff members could not understand. Despite this provision, none of the prisons involved in the research made these recordings available to potential participants. In all instances I was advised that establishments were unable to show the video to participants because of either security restrictions or a lack of available facilities. Consequently, a number the Deaf participants were only able to give informed consent on the day of the interview when the interpreter was able to translate the necessary information into BSL for them, thus meaning that the prisons themselves were violating the stipulations of NOMS.

Another important ethical consideration related to the welfare of participants. It was anticipated that discussions around the pains of imprisonment and communication isolation might provoke feelings of distress/anxiety. In order to ensure that this was kept to a minimum, participants were advised in the information sheet and at the start of the interview that their participation was voluntary, and that the interview could be paused or terminated at any time if they so wished. This ethical consideration was most applicable to one Deaf participant who became very upset when discussing his experience in prison. On multiple occasions I asked him if he was okay, and advised that we did not have to carry on with the interview. 
However, despite being outwardly distressed he was adamant that we needed to continue because he wanted to do all he could to improve the situation for Deaf prisoners in the future. Such distress was very difficult and upsetting to witness, whilst also being difficult to manage, as shown here in an extract from my fieldwork journal; "I found it very difficult to know how to react without seeming insincere. I desperately wanted him to know that I did actually care about what he was saying, and that it was affecting me, but again felt helpless as to what I could do to counteract such pain" (7th May 2015).

Also relevant to the welfare of participants was the option of aftercare for individuals who became distressed during the interview. Interviewees were advised within the information sheet that I would be able to supply information regarding avenues of support if they so wished. This became relevant six months after the fieldwork period had ended when I provided one Deaf participant with information regarding appropriate support avenues. This individual had written to me on numerous occasions after the interview, and within his letters indicated that he felt very lonely and isolated in prison as a consequence of his Deafness. He also wrote about having minimal contact with family members and feeling relieved that he had somebody to talk to about his life. Although I did respond to him on numerous occasions, I felt that I was not equipped to provide the emotional support that he was looking for, as highlighted in the following extract from my fieldwork journal:

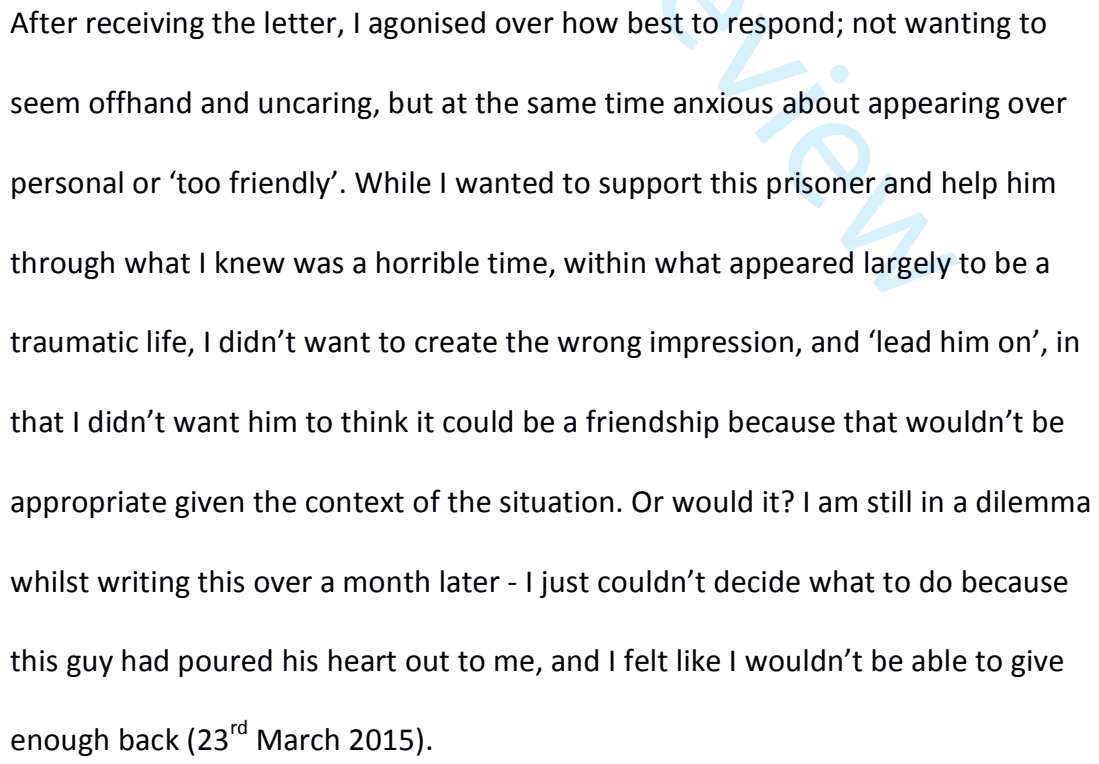

After discussing the situation with my supervisory team, I wrote to the individual advising him of the existence of a befriending service provided by an external organisation (New Bridge Foundation, 2016) which I thought 
could potentially help to reduce some of the isolation he was feeling. Instances such as this provoked feelings of moral and ethical contradiction as although I had done my utmost to avoid compromising the welfare of my participants, I felt as though involvement in my research may have had negative repercussions in the long term for him (for similar findings, see also Scraton \& Moore, 2013; Crewe \& levins, 2015)

\section{Protecting Against the Inevitable: Subjectivity}

After considering the intricacies of the interview process and the complexities of carrying out research with $d /$ Deaf people in prison, the impact that $I$, the researcher, had on the research is now discussed. Before the fieldwork began I was conscious that if I wanted to address my research aims I would need to create an accurate picture of the participants' realities and responses (Morris \& Morris, 1963; Scott, 2006). My priority was to ensure that the views of the participants remained at the heart of the research, and that if they were to see it, the interviewees would be able to relate to the findings (Scott, 2015a). However, completely neutrality in qualitative social research is of course impossible, and rather an individual's research is inevitably shaped by their values, attitudes and interpretations, and unavoidably considered through their own unique biographical lens (Cohen \& Taylor, 1972; King \& Elliott, 1977; Genders \& Player, 1995; Liebling, 1999; Phillips, 2012; Hammersley, 2015; Scott, 2015b). This became evident during my second visit to HMP Bowdon, where I realised that my unconscious opinions regarding $d$ /Deafness had influenced the way that I had viewed the participants during my first visit, as detailed in the following extract from my fieldwork journal:

When one of the psychology staff members spoke of P1B being very manipulative during one to one sessions with her, and crying in order to get himself 'out of trouble' I couldn't help but feel shocked. In my head, despite consciously trying not to, I had oversimplified the characters of the Deaf prisoners I had interviewed, and found it difficult to comprehend them being manipulative or vicious purely because they were Deaf. This was extremely frustrating as it brought home to me that I am still a member of the hearing world no matter how much I try to separate myself. No matter what I do, I will never be Deaf, and am unlikely ever to be able to rid myself of these ingrained perceptions of 'deafness' and 'difference' and 'disability' (16 ${ }^{\text {th }}$ March 2015). 
emotions who seem so 'normal' had all committed terrible offences $\left(19^{\text {th }}\right.$ February

2015).

Not only was this difficult mentally, but at times there was also a danger of it affecting the interviews. On a number of occasions, I had to consciously fight the desire to question the participants about the details of their offences in a bid to gain an understanding of the motives behind them. The fact that the prisoners often appeared so 'normal ' also made the research experience more emotionally challenging than I had anticipated, because it became difficult to rationalise the pain that they were experiencing. This is shown in the following extract from my fieldwork journal:

Again, I struggled mentally during my time with P5B. When he was discussing the problems that he had had throughout his life I just felt awful for him. I found it very sad that he spoke of always being isolated, and feeling uncomfortable in the presence of others. He was very honest during the interview and at the end, he said that he had been extremely nervous beforehand and had been shaking. I couldn't help but warm to him, but then, again felt very mentally disoriented and strange because he was a repeated child sex offender. After this interview was over, I was completely exhausted, and felt depressed and upset at what the prisoner had told me $\left(16^{\text {th }}\right.$ March 2015).

Once I had actually experienced the prison environment for myself I began to understand why prison researchers (for example Liebling, 2001; Bosworth et al., 2005; Phillips, 2012; Stevens, 2013; Crewe, 2014; Drake \& Harvey, 2014; Earle, 2014; Jewkes, 2014; Piacentini, 2015) are now devoting increasing amounts of time to discussing the role that emotions play in the research process. I found the whole fieldwork experience to be emotionally exhausting and more mentally testing than I had ever imagined, and I would often leave interviews feeling physically sick and mentally overwhelmed. Although I was theoretically prepared for what I might see/hear in prison, in reality seeing the pains experienced by $d /$ Deaf prisoners through my own eyes was very different from reading about them on paper, and in hindsight I was not prepared to be exposed to real human suffering in the way that I was. 
While experiencing such feelings was difficult, it arguably enhanced the quality and depth of the research (Sloan \& Drake, 2013), in that in certain instances my emotions acted as what Jewkes (2012) calls an “intellectual resource" (pp. 66). By being "emotionally sensitive" (Crewe, 2014, pp. 426), I was able to empathise with the feelings of participants in a way that helped me to gain more insight into their lived realities. However, I was also aware that emotional involvement on the part of the researcher can have the potential to undermine the authenticity of their research if it is not adequately regulated, as an individual can begin to prioritise the opinions of participants with whom they empathise with the most at the expense of others (Sparks et al., 1996, Stevens, 2013). Therefore, to ensure that the data was as accurate as possible and to avoid becoming "contaminated by sympathy" (Ruess, 2000, pp. 40) I implemented what Crewe (2014) calls "reflexive interrogation" (pp. 394). During this process I regularly critically reflected on my emotions and standpoint in a variety of ways; internally, with my supervision team and by keeping a fieldwork journal. Through this continuous critical self-reflection I was able to keep sight of the fact that my overarching priority was to address my research aims, and that although subjectivity was inevitable, and empathy was natural and even useful, I needed to maintain a professional boundary between myself and the participants.

\section{Concluding Remarks and Recommendations}

This article has provided an outline of my experience of doing research with d/Deaf people in prison, including the process of gaining access, the interviews, ethics, recording and transcription and the management of inevitable subjectivity. It is evident that the research process was laden with complex obstacles, some of which mapped onto those of other researchers and were produced by the nature of the environment itself, and others that went beyond this. The fact that this study is the first in England and Wales to include semistructured interviews with multiple d/Deaf prisoners (excluding small-scale unpublished undergraduate dissertations), meant that it was methodologically unique. This introduced uncertainty and generated an array of additional hurdles, as have been discussed throughout. A key hurdle related to access; without a meaningful mechanism in place for recording d/Deaf prisoner numbers it was extremely hard to locate appropriate research participants. This, combined with a lack of $d$ /Deaf awareness on the part of allocated contacts led to the eventual widening of the research sample to include prisoners across the hearing-Deaf spectrum. Further methodological complications arose as a result of the language barriers between myself and the Deaf prisoners, with their preference for a visual language making the process of ensuring that the research was 
both ethical and authentic more difficult than it otherwise would have been. Such difficulties were compounded by the fact that I was not able to bring visual recording devices into establishments, nor were the Deaf participants given access to visual copies of my consent forms and information sheets.

My experiences provide a framework for prospective researchers on how to carry out research with d/Deaf people in prison. While existing sources have examined the process of doing research with d/Deaf people and in prisons separately, the process involved when the two scenarios combine has not previously been documented. Thus, by discussing how to go about carrying out research in a heavily regulated, secure environment like prison with a sample of $d$ /Deaf people with culturally distinct norms and language, this article makes a significant contribution to qualitative research methods literature. The inclusion of a transparent account of the methodological issues I faced is particularly noteworthy, in that it will allow future researchers to anticipate such issues before they arise, thus simplifying the process and enabling them to prepare accordingly. The fact that the research process documented my journey as a hearing person with little comprehension of BSL means that the article is of most obvious significance for other hearing researchers. However, it is of value to Deaf scholars too given that many of the methodological complications I faced were generated by the nature of the prison environment as a research setting rather than my hearing status/language preference. As such, discussions about access, recording, researcher identity, subjectivity and ethics will also be of significance to Deaf researchers. However, it is likely that the Deaf status of such individuals will alter the way that these methodological complications are experienced, thus making publications in this area a necessity.

What follows now is a list of recommendations I would extend to others considering doing research with d/Deaf prisoners:

1. A year was allocated for gaining access and carrying out the fieldwork during this research, which was much too short. The process of locating appropriate participants took much longer than expected, as did liaising with individual prisons and organising interviews. Consequently, after the fieldwork period had ended, establishments continued to express an interest in being involved, and although such involvement may have enhanced the quality of the data collected, time constraints meant that I had to decline offers of interviews. 
Thus, it is recommended that future researchers carry out larger projects with more leeway in terms of timescales.

2. The dual process of gaining NOMS clearance and ethical approval from the University was particularly difficult during this research because neither would give approval without evidence of approval from the other. To combat this, individuals can obtain 'approval in principle' from the relevant ethics committee prior to being awarded clearance by NOMS (now HMPPS). Once clearance to carry out research in prisons is awarded, a full ethics application can then be submitted.

3. If a BSL interpreter is being used in interviews with culturally and linguistically Deaf participants, it is imperative that they are registered with the NRCPD, and preferable that they have experience with interpreting in environments like prison. Researchers must also ensure that interpreters are sufficiently briefed about the research and the remit of their role before any interviews are carried out.

4. It is recommended that where at all possible, all interviews with culturally and linguistically Deaf prisoners are recorded via a visual recording device. In instances where an interpreter is being used, this would ensure complete authenticity rather than merely recording the interpreter's interpretation of the raw data (which is what a Dictaphone does). This would also be beneficial for transcription, as it would mean that a copy of the raw data would be available for the researcher to refer back to after the fieldwork period is over, thus minimising the margin for error. It would also eliminate issues with regards to Deaf participants speaking over the interpreter's translation of their BSL, which, in this research made certain interpretations indecipherable. If the option to visually record an interview with a Deaf person is not available, it is recommended that two Dictaphones could be used instead; one to record the interview, and another to record the researcher's/interpreter's ${ }^{15}$ dialogue during the interview. In order to do this, the interpreter would need to plug a headset into the Dictaphone (or use a wireless equivalent), which would enable the recording to be focused around their voice, thus preventing any distortion.

5. In order to collect sufficiently rich data from Deaf prisoners, it is recommended that where feasible, participants are interviewed in groups as well as individually. In the context of this research Deaf participants were much more open and engaged when discussing their experiences with others who were Deaf. If group interviews are carried out, it would be beneficial to utilise the services of multiple interpreters, as this would be make it easier for complex and flurried conversations to be interpreted comprehensively.

\footnotetext{
${ }^{15}$ If the researcher was able to communicate fluently in BSL, then an interpreter would not necessarily be required.
} 
6. To ensure that the research is ethical, Deaf participants should be provided with visual copies of information sheets and consent forms prior to being interviewed. In order to prevent establishments declining to do this, the importance of this must be made explicit in any application documents.

\section{References}

Action on Hearing Loss (n.d.). Definitions of Deafness. Retrieved from

https://www.actiononhearingloss.org.uk/your-hearing/about-deafness-and-hearing-loss/definitions-ofdeafness.aspx.

Atherton, M., Russell, D., \& Turner, G.H. (2001). Looking to the past: the role of oral history research in recording the visual history of Britain's Deaf community. Journal of Oral History, 29(2), 35-47

Almalik, M., Kiger, A., \& Tucker, J. (2010). "What did she say? What did she say?" The Impact of Interpretation on Recruiting and Interviewing European Migrant Women in the United Kingdom. International Journal of Qualitative Methods, 9(3), 252-269

Bosworth, M., Cambell, D., Demby, B., Ferranti, S. M., \& Santos, M. (2005). Doing Prison Research: Views from Inside. Qualitative Inquiry, 11, 249-264

Bryman, A. (2012). Social Research Methods ( $4^{\text {th }}$ Ed). Oxford: Oxford University Press

Cohen, S., \& Taylor, L, (1972). Psychological Survival. Hammondsworth: Penguin

Crawley, E. (2004). Doing Prison Work: The Public and Private Lives of Prison Officers. Cullompton: Willan

Crewe, B. (2009). The Prisoner Society: Power, Adaptation and Social Life in an English Prison. Oxford: OUP,

Clarendon

Crewe, B. (2011). Depth, weight, tightness: Revisiting the pains of imprisonment. Punishment and Society, 13, $509-529$

Crewe, B. (2014). Not looking hard enough: masculinity, emotion and prison research. Qualitative Inquiry, 20(4), 426-437

Crewe, B., \& levins, A. (2015). Closeness, Distance and Honesty in Prison Ethnography. In D. Drake, R Earle, \& J, Sloan. (Eds) The Palgrave Handbook of Prison Ethnography (pp. 124-142). Basingstoke: Palgrave

Davies, P. (2011). Doing Interviews in Prison. In P. Davies, P. Francis \& V. Jupp. (Eds) Doing Criminological

Research ( $2^{\text {nd }}$ ed., pp. 161-178). London: Sage

Drake, D. (2012). Prisons, Punishment and the Pursuit of Security. Basingstoke: Palgrave 
1

2

3

4

5

6

7

8

9

Drake, D., \& Harvey, H. (2014). Performing the role of ethnographer: processing and managing the emotional dimensions of prison research. International Journal of Social Research Methodology, 17(5), 489-501 Earle, R. (2014). Insider and Out: Making sense of a prison experience and a research experience. Qualitative Inquiry, 20, 429-438

Emery, F. E. (1970). Freedom and Justice within Walls: The Bristol Prison Experiment. London: Tavistock Gelsthorpe, L. (1990). Feminist methodologies in criminology: a new approach or old wine in new bottles?. In L. Gelsthorpe, \& A. Morris. (Eds) Feminist Perspectives in Criminology (pp 89-106). Milton Keynes: Open University Press Genders, E., \& Player, E. (1995). Grendon: A Study of a Therapeutic Prison. Oxford: Oxford University Press Hammersley, M. (2015). Research 'Inside' Viewed from 'Outside': Reflections on Prison Ethnography. In D Drake, R. Earle, \& J. Sloan. (Eds) The Palgrave Handbook of Prison Ethnography (pp. 21-39). Basingstoke: Palgrave Harris, J. (2010). Boiled Eggs and Baked Beans - A personal account of a hearing researcher's journey through Deaf culture. Disability and Society, 10(3), 295-308 Higgins, P. (1980). Outsiders in a Hearing World: A sociology of deafness. London: Sage Ingvarsdotter, K., Johnsdotter, S., \& Ostman, M. (2010). Lost in interpretation: The use of interpreters in research on mental ill health. Int J Soc Psychiatry, 58, 34-40 Jewkes, Y. (2002). Captive Audience, Cullompton: Willan Publishing Jewkes, Y. (2012). Autoethnography and Emotion as Intellectual Resources: Doing Prison Research Differently. Qualitative Inquiry, 18, 63-75 Jewkes, Y. (2014). An Introduction to “Doing Prison Research Differently". Qualitative Inquiry, 20, 387-391 Kelly, L. (2017). Suffering in Silence: The unmet needs of d/Deaf prisoners. Prison Service Journal, November 2017,234

Kelly, L. (2018). Sounding out d/Deafness: The experiences of d/Deaf prisoners. Journal of Criminal Psychology, $8(1), 20-32$

King, R.D., \& Elliott, K. (1977). Albany: Birth of a Prison. London: Routledge King, R.D., \& Liebling, A. (2008). Doing research in prisons. In R.D. King, \& E. Wincup. (Eds) Doing research on crime and justice ( $2^{\text {nd }}$ ed., pp. 431-451). Oxford: Oxford University Press King, R.D., \& McDermott, K. (1995). The State of our Prisons. Oxford: Oxford University Press 
Leigh, I. W. (2009). A Lens on Deaf Identities. New York: Oxford University Press

Liebling, A. (1999). Doing Research in Prison: Breaking the Silence?. Theoretical Criminology, 3: 147-172

Liebling, A. (2001). Whose Side Are We On? Theory, Practice and Allegiances in Prison Research. British Journal of Criminology, 41, 472-484

Marschark, M. (1993). Origins and Interactions in Language, Cognitive and Social Development in Deaf

Children. In M, Marschark. \& M.D, Clarke. (Eds) Psychological perspectives on deafness (pp. 7-26). Hillsdale:

Erlbaum

Martin, C. (2000). Doing research in a prison setting. In V. Jupp, O. Davies, \& P. Francis. (Eds) Doing

Criminological Research (pp. 215-233). London: Sage

Matthews, B., \& Ross, L. (2010). Research Methods: A Practical Guide for the Social Sciences. Harlow: Longman McCulloch, D. (2010). Not hearing us? A critical exploration of the current experiences of profoundly deaf prisoners in Anglo Welsh prisons. (unpublished dissertation). Birmingham: Birmingham City University McCulloch, D. (2012). Not Hearing Us: An exploration of the experience of deaf prisoners in English and Welsh prisons. A Report for the Howard League for Penal Reform. London: The Howard League for Penal Reform Ministry of Justice. (n.d.). Prison National Offender Management Information System (p-NOMIS) and Inmate Information System (IIS). Retrieved from https://data.gov.uk/dataset/prison-national-offender-managementinformation-system-p-nomis-and-inmate-information-system-ii Moore, L. and Scraton, P. (2013). The Incarceration of Women: Punishing Bodies, Breaking Spirits. London: Palgrave

Morris, T., \& Morris, P. (1963). Pentonville. London: Routledge

Murray, C.D., \& Wynne, J. (2001). Using an interpreter to research community, work and family. Community, Work and Family, 4(2), 157-170

National Registers of Communication Professionals working with Deaf and Deaf blind People. (n.d.a). About Us. Retrieved from http://www.nrcpd.org.uk/index.php National Registers of Communication Professionals working with Deaf and Deaf blind People. (n.d.b). Code of Conduct. Retrieved from http://www.nrcpd.org.uk/code-of-conduct New Bridge Foundation (2016). About Us. Retrieved from http://www.newbridgefoundation.org.uk/aboutus/overview/ Padden, C. (1980). The Deaf Community and the Culture of Deaf People. In C, Baker. \& R, Battison. (eds) Sign 
1

2

3

4

5

6

7

8

9

Language and the Deaf Community: Essays in Honour of William (pp. 89-104). Silver Spring MD: National Association of the Deaf

Phillips, C. (2012). The Multicultural Prison: Ethnicity, Masculinity, and Social Relations among Prisoners. Oxford: Oxford University Press

Reuss, A. (2000). The Researcher's Tale. In D, Wilson. \& A, Reuss. (eds) Prison(er) Education: Stories of Change and Transformation (pp. 24-47). Hook: Waterside Press

Rowe, A. (2014). Situating the Self in Prison Research: Power, Identity and Epistemology. Qualitative Inquiry, 20: $404-416$

Roy, C.B. (1992). A sociolinguistic analysis of the interpreter's role in simultaneous talk in a face-to-face interpreted dialogue. Sign language Studies, 74 [Spring 1992]

Schlosser, J.A. (2008). Issues in Interviewing Inmates: Navigating the Methodological Landmines of Prison Research. Qualitative Inquiry, 14(8), 1500-1525

Scott D. (1996). Heavenly Confinement? The Prison Chaplain in North East England's Prisons. London: Lambert Press

Scott, D. (2006). Ghosts beyond our realm: A Neo-Abolitionist Analysis of Prisoner Human Rights and Prison Officer Occupational Culture Preston: University of Central Lancashire

Scott, D. (2015a). Critical research values and the sociological imagination: Lessons from researching prison officers. In, J. Frauley. (Ed) C. Wright Mills and the Criminological Imagination (pp. 185-199). Aldershot: Ashgate Scott, D. (2015b). Walking amongst the graves of the living: Reflections about doing prison research from an abolitionist perspective. In D. Drake, R. Earle, \& J. Sloan. (eds) The Palgrave Handbook of Prison Ethnography (pp. 40-58). Basingstoke: Palgrave

Sloan, J., \& Wright, S. (2015). Going in Green: Reflections on the challenges of 'Getting in, getting on, and getting out' for doctoral prisons researchers. In D. Drake, R. Earle, \& J. Sloan. (Eds) The Palgrave Handbook of Prison Ethnography (pp. 143-168). Basingstoke: Palgrave Sparks, R., Bottoms, A., \& Hay, W. (1996). Prisons and the Problem of Order. Oxford: Clarendon Press Stevens, A. (2013). Offender Rehabilitation and Therapeutic Communities: Instituting Change 'the TC Way'. New York: Routledge Stone, C. \& West, D. (2012). Translation, representation and the Deaf 'voice'. Qualitative Research, 12(6), 645 - 
665

Sutherland, H., \& Young, A. (2014). Research with deaf children, not on them: a study of method and process, Children and Society, 28(5), 366-379

Wadensjö, C. (1998). Interpreting as Interaction. London \& New York: Longman

Wincup, E. (2017). Criminological Research: Understanding qualitative methods $\left(2^{\text {nd }}\right.$ ed). London: Sage

Wincup, E., \& Hucklesby, A. (2007). Researching and Evaluating Resettlement. In A. Hucklesby, \& L. Hagley-

Dickinson. (eds) Prisoner Resettlement: Policy and Practice (pp. 67-94). Cullompton: Willan

Wilson, A.T., \& Winiarczyk, R.E. (2014). Mixed methods research strategies with Deaf people: Linguistic and

cultural challenges addressed. Journal of Mixed Methods Research, 8(3), 266-277

Young, A., \& Hunt, R. (2011). Research with d/Deaf people: Methods Review 9. London: National Institute for Health Research

http://mc.manuscriptcentral.com/qi 